\title{
Does the instructional quality of community- based clinical clerkships influence students' career preferences?
}

\author{
Masanobu Okayama, Eiji Kajii \\ Division of Community and Family Medicine, Centre for Community Medicine, Jichi Medical University, Japan
}

Correspondence: Masanobu Okayama, Division of Community and Family Medicine, Centre for Community Medicine, Jichi Medical University, Japan. Email: okayama@jichi.ac.jp

\begin{abstract}
Objectives: The purpose of this study was to explore the association between student evaluation of their communitybased clinical clerkship, their attitudes towards community health care and their career preferences.

Methods: Self-administered pre- and post-questionnaire surveys were given to 693 fifth-year medical students participating in a two-week community-based clinical clerkship. Items measured were student preference for a career in primary care, student evaluation of the programme and student attitudes towards community health care.

Results: Six hundred and forty-five students (93.1\%), 494 (76.6\%) male and 151 (23.4\%) female, completed the preand post-questionnaires. Student preference for a career in primary care $(75.4 \pm 20.2)$ increased after the clinical
\end{abstract}

clerkship. By multivariate analysis, it was found that evaluation of the programme ('The programme was a worthwhile learning experience.' [multivariate regression coefficient: 0.143, $\mathrm{p}=0.014]$ ) and their attitude ('I think practising community health care is worthwhile.' [0.367, $\mathrm{p}<0.001]$ ) were strongly associated with the increase in preference for a career as a primary care physician after the clinical clerkship.

Conclusions: Community-based education increases student preference for a future career as a primary care physician. Providing programmes of a high instructional quality further increases the chance of student physicians choosing a future career as a primary care physician.

Keywords: Primary care physician, career preference, community-based education, clinical clerkship, evaluation

\section{Introduction}

Primary care physicians have been contributing to improvements in health outcomes at a lower cost and for more people. ${ }^{1}$ However, a shortage of primary care physicians in the community, especially in rural and underserved areas, has still been a political concern in many countries, including Japan. ${ }^{2-4}$ In an attempt to address the issue, a couple of proposals for medical education concerning primary care have been reported.,6 Furthermore, in the 2000s, the Japanese government changed the way medical education was taught, shifting the focus to primary care and general medicine, and introducing a model core curriculum and a new initial postgraduate clinical training programme. ${ }^{7,8}$ All 79 Japanese medical schools were expected to implement the model core curriculum using $70 \%$ of existing contact hours to achieve their school-specific curriculum goals. ${ }^{8}$ In
2007, it adopted a clinical training program in the community. ${ }^{9}$

Thus, in Japan, community-based education was established as a mandatory clinical training program. Previous studies suggest that the quality of clinical training in community-based settings is a factor influencing and increasing student preferences for practising primary care. ${ }^{5,10}$ Community-based clinical clerkships differ considerably between schools, including Japanese medical schools. ${ }^{11-13}$ Thus, ensuring high instructional quality of the community-based clinical programme is a critical issue. Academic staff in charge of planning programmes have tried to improve them in accordance with student evaluations. ${ }^{14-16}$ It is essential that these efforts lead to increased numbers of students having a preference for practising primary care. 
A few studies investigating an association between student feedback on their community-based education and their preference for a career as a primary care physician have been undertaken. ${ }^{17,18}$ The findings of these studies were inconsistent and the association between the two factors has remained ambiguous.

Community-based education is an approach that aims to prepare students for future professional work at the community level. ${ }^{19}$ In addition to student feedback, it is important to explore the association between student attitudes towards community health care and career preferences.

Knowing these associations will clarify whether providing high quality community-based education programmes will lead to an increase in students choosing a career as a primary care physician or not. The purpose of this study was to explore the association between student evaluations and their attitudes towards community health care, and their preferences for a career as a primary care physician.

\section{Methods}

\section{Community-based clinical education at Jichi Medical University}

The details of the community-based clinical education programmes at Jichi Medical University (JMU) have been previously reported. ${ }^{20}$ JMU is a publicly funded medical school whose aim is to produce doctors who practice community health care in rural and underserved areas. JMU recruits two or three high-school graduates annually from each of the 47 prefectures of Japan. All students sign contracts with their home prefectures and JMU. They are fully funded by the home prefectures for the entire six years of undergraduate education at JMU and commit to working for a public medical institution in their home prefecture for nine years after graduating from JMU. Thus the students pay no tuition or school fees for the entire six years at JMU. After nine years if they so desire, they are able to continue to work in a public medical institution in their home prefecture. JMU put emphasis on the community-based medical education. However, the curriculum at JMU is not so different from at the other Japanese universities.

Community-based clinical education at JMU is a twoweek clinical clerkship in a community hospital or clinic in rural and underserved areas in the students' home prefectures. ${ }^{21}$ The community-based clinical training at JMU is longer than others, because the duration of most programmes at the others is within two weeks. ${ }^{22}$ The purposes of the programme at JMU are as follows: to promote an understanding of community needs and circumstances (e.g. culture, customs, social resources and personal relationships), to teach about the role of physicians practising in a community setting and to increase the motivation of student physicians to practice community health care. These are similar to the generic purposes of the community- based education in the revised model core curriculum. ${ }^{9}$ That's why the purposes of the clinical clerkship in the community at JMU are not different from at the other Japanese universities.

In the clinical clerkship, the students are under the supervision of one or two physician teachers in each of the 47 prefectures. These supervisors are trained in teaching skills and appointed as regional faculty members of JMU. Although the faculty at JMU organize and manage the programme and ensure instructional quality, the regional faculty members themselves determine the programme's processes in accordance with standards for 11 learning activities, which include ambulatory care, home care, hospital care, placement in mobile clinics, on-call work, rehabilitation, health education, health check-ups, vaccination, day services and placement in welfare facilities (welfare institutions or nursing homes for the aged). ${ }^{23}$

In Japan, primary health care is provided by clinics and community hospitals. In urban, most of them are private sectors. On the other hand, in rural and underserved areas, most of them are public ones. During two weeks, students posted in one or more discipline among primary care, general internal medicine, general surgery, and general pediatrics. According to circumstances of each teaching hospital or clinic, the regional faculty members provided learning activities as many as possible to each student. The students experienced each learning activity in a day or in half a day and were taken feedback for their performance by the physician teachers.

\section{Participants and measurements}

From 2003 to 2009, a self-administered questionnaire was given to 693 fifth-year medical students who were participating in a two-week community-based clinical clerkship. The students were given the questionnaire to complete before and after the clerkship. Measurement items were gender, medical institutions in the clerkship, experience or not of the 11 learning activities described above, student evaluations of the programme, student attitudes towards community health care and their attitudes towards career preference. The items evaluating the programme were 'The physician teachers were enthusiastic', 'The physician teachers took enough time' and 'The programme was a worthwhile learning experience'. The items on attitudes were 'I think practising community health care is worthwhile', 'I am confident about practising community health care', 'I want to become a generalist in the future' (generalist) and 'I want to become a specialist in the future' (specialist). The generalist in Japan is equivalent to a primary care physician in USA and a general practitioner in UK. The student evaluations and attitudes were obtained using a visual analogue scale (VAS, $0-100$ ). The VAS was a horizontal line of $100 \mathrm{~mm}$ length with two extreme states, which are "definitely negative (were/was/am/did/do not)" and "definitely positive (were/was/am/did/do)", anchored at 
each end. The students were required to place a mark (X) on the line. A distance between the left end and the mark was determined as a VAS score. The attitudes were queried in both the pre- and post-questionnaire, and other measurements were performed only post-questionnaire. Students were identified using their student identification number. This number was used to match the pre- and postquestionnaires. We assured the students that their responses would not affect their academic standing, and we did not have access to all of the students' records. The Bioethics Committee for Jichi Epidemiologic Research, Jichi Medical University, approved this study as exempt based on the Japanese bioethical guidelines for epidemiological and clinical research.

\section{Analysis}

Before statistical analyses were performed, the training setting was classified into three types: hospital, hospital and clinic or clinic. Student experience was classified into three groups based on the number of learning activities experienced: 1-4 activities, 5-7 activities or 8-11 activities.

Statistical analyses were performed using Stata/SE 11.2 for Windows (StataCorp. LP, USA). The statistical significance level was set to less than 0.05 . We calculated the proportion and mean \pm standard deviation (SD) for the categorical and continuous data, respectively. We analysed the difference in student attitudes towards career preference before and after their clerkship by paired t-test, between male and female by unpaired t-test and among training settings and number of learning activities by one-way ANOVA. Pearson's correlation coefficient was used to assess the relationship between the difference in student attitudes towards career preferences before and after the clerkship, the student evaluations of the programme, student attitudes towards community health care after the clerkship and the difference in them before and after the clerkship. After the bivariate analyses, a multiple regression analysis as a multivariate analysis was used to determine factors independently related with the difference in student attitude towards career performance before and after the clerkship. A multiple regression coefficient was obtained adjusting the variables that were significantly related in the bivariate analyses.

\section{Results}

Of 693 students, 645 (93.1\%) completed the pre- and postquestionnaires. Demographic characteristics are shown in Table 1. The student evaluations of the programme and student attitudes towards community health care are shown in Table 2. The VAS scores of student career preference for 'generalist' and 'specialist' after the clerkship were $75.4 \pm$ 20.2 and $64.5 \pm 21.0$, respectively, (Table 3 ). The VAS score of 'generalist' increased significantly after the clerkship, but the VAS score of 'specialist' did not.

Gender, training settings, and the number of learning activities were not associated with the differences in the
VAS scores of student career preference for 'generalist' and 'specialist' before and after the clerkship.

Table 1. Demographic characteristics $(N=645)$

\begin{tabular}{lcc}
\hline Variables & $\mathrm{N}$ & $\%$ \\
\hline Gender & & \\
Male & 494 & 76.6 \\
Female & 151 & 23.4 \\
Training settings & \multicolumn{2}{c}{} \\
Hospital & 237 & 36.7 \\
Hospital and clinic & 355 & 55.0 \\
Clinic & 53 & 8.2 \\
Number of learning activities (Mean \pm SD) & \multicolumn{2}{c}{$7.8 \pm 1.8$} \\
1-4 activities & 30 & 4.7 \\
5-7 activities & 225 & 34.9 \\
8-11 activities & 390 & 60.5 \\
\hline
\end{tabular}

In bivariate analysis (Table 4), student evaluation of the programme, student attitudes towards community health care after the clerkship and the differences between them before and after the clerkship were positively associated with the difference in the VAS score of 'generalist' between before and after the clerkship. However, these items were not positively associated with those of 'specialist'. In multivariate analysis, one of the items used to assess student evaluations of the programme 'The programme was a worthwhile learning experience.' (multivariate regression coefficient: $0.143, \mathrm{p}=0.014$ ) and one of the items used to assess student attitudes towards community health care 'I think practising community health care is worthwhile.' between before and after the clerkship $(0.367, \mathrm{p}<0.001)$ were independently associated with the difference between the before and after clerkship VAS scores for 'generalist'.

Table 2. Student evaluations of the programme and student attitudes towards community health care $(N=645)$

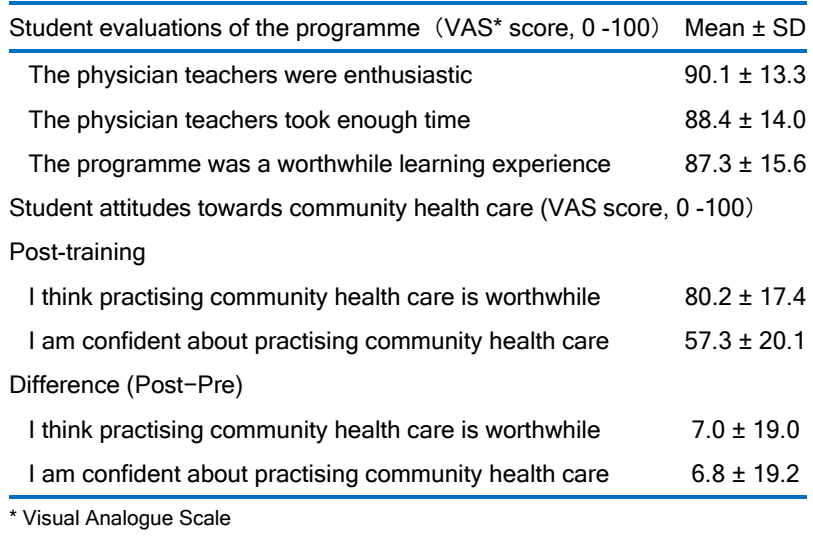

\section{Discussion}

In this study, student evaluation of the programme and their attitudes towards community health care were associated with positive changes towards a preference for a career as a primary care physician, through the clinical clerkship. In addition, consistent with the previous studies measuring 
career choice, ${ }^{24-26}$ this study has shown that student preference for practising as a primary care physician increases after community-based clinical clerkships, but student preference for working as a specialist does not.

Table 3. Student attitudes towards career preferences $(N=645)$

\begin{tabular}{lllll}
\hline & \multicolumn{3}{c}{ Visual analogue scale score $(0-100)$} & \\
\cline { 2 - 4 } Student attitudes & \multicolumn{3}{c}{ Mean \pm SD } \\
\cline { 2 - 4 } & Pre-training & Post-training & $\begin{array}{c}\text { Difference } \\
\text { (Post-Pre) }\end{array}$ & \\
\hline $\begin{array}{l}\text { I want to become a } \\
\text { generalist in the } \\
\text { future }\end{array}$ & $70.2 \pm 22.4$ & $75.4 \pm 20.2$ & $5.2 \pm 20.2$ & $<0.001$ \\
$\begin{array}{l}\text { I want to become a } \\
\text { specialist in the } \\
\text { future }\end{array}$ & $64.9 \pm 20.3$ & $64.5 \pm 21.0$ & $-0.4 \pm 20.8$ & 0.607 \\
\hline
\end{tabular}

Defining and measuring the components of medical education have been limited by the lack of an effective research model and an evaluation strategy. ${ }^{27}$ However, Shipengrover and James $^{28}$ proposed a model concerning instructional quality in community-based education. In the model, physicians responsible for community needs were defined as outcomes, and student satisfaction with the education was seen as an intermediary. By measuring these outcomes, one could assess the aspects of curriculum instruction, which were course design, physician teacher performance and the programme of staff development. The delivery of instruction in community-based education is a process under the physician teacher's control. Course directors are unable to oversee these training sites. Thus, evaluation of student satisfaction with the programmes and their attitude towards community health care are considered appropriate tools to measure the quality of programmes. In other words, a high quality programme is able to receive good evaluations from students. Thistlethwaite et al. ${ }^{29}$ claimed that attention needed to be paid to the quality of the general practice learning experience to achieve a more positive effect on career choice. Planners of community-based education need to put more effort into evaluating and improving their programmes.

This study had some limitations. First, student gender and hometown are significant factors associated with student career choice, ${ }^{30,31}$ but this study only examined gender as a potential factor. The proportion of female medical students were about $50 \%$ in many countries, and in Japan, according to the government report, ${ }^{32}$ it is $46 \%$. The proportion of female students in this study was less than the Japanese average. Gender was not associated with attitude towards primary care in this study. Second, the subjects in this study (students in JMU) had the opportunity about once a year to visit hospital or clinic in rural or underserved areas other than during the clerkship. Although the duration of visit in the hospital or clinic is one or two day, the purposes of the visit are similar to the clinical clerkship in the community. Thus before the clinical clerkship, the students in JMU were probably already strongly interested in practising in the community setting. Interest in community health care may be an important influencing factor on career preferences. It is unclear whether community-based education has the ability to motivate previously uninterested students to consider a career in primary care ${ }^{33}$ To clarify the association between the students' previous interest in primary care and the effect of community-based education is a future research question. Third, the Japanese medical system does not have a formally certified primary care discipline. ${ }^{34}$ There are few teaching hospitals providing residency programme in primary care. All students in JMU after graduation cannot take appropriate postgraduate training for a generalist. Many students have to learn and develop skills necessary to become a generalist through individual effort.

Although these possibly influence student career preferences, the findings regarding career preference in this study are possibly underestimated rather than overestimated. Thus, Japanese circumstances do not weaken our conclusion. Fourth, the total duration of the clinical clerkship in JMU was two weeks. Thus each activity has taken a day or half a day. In this case, it might be very limited exposure for anyone to change his/her mind. However it is unclear what effect these things have on the findings in this study. Fifth, the findings in this study are short-term effects on student attitudes concerning career preferences. The differences in the VAS score of the career preferences between after and before the clerkship are defined as the effects on them. The findings in this study cannot estimate the number of the students who want to be primary care physician. This intervention is not well structured and is under very limited supervision by the university. Further research will be needed to explore whether the effects of high quality community-based education programmes lead to increased numbers of student physicians choosing careers as primary care physicians.

\section{Conclusion}

Community-based education increases student preferences for primary care as a future career. Providing communitybased education programmes of high instructional quality probably further increases student preferences for practising as primary care physicians in the future. Given this, course directors need to put more effort into evaluating and improving community-based education programmes for student physicians.

\section{Acknowledgements}

The authors would like to thank Noriko Satou, Naoko Arakawa and Kimie Ueki for administrative assistance. We are also grateful to all the students who participated in the study. This study was not supported by any funding. 


\begin{tabular}{|c|c|c|c|c|c|c|}
\hline \multirow{2}{*}{ Student perceptions of the programme } & \multicolumn{4}{|c|}{ Generalist* } & \multicolumn{2}{|c|}{ Specialist* } \\
\hline & Bivariate $^{\dagger}$ & $p$ value & Multivariate ${ }^{\ddagger}$ & $\mathrm{p}$ value & Bivariate $^{\dagger}$ & $\mathrm{p}$ value \\
\hline \multicolumn{7}{|l|}{ Student evaluations of the programme } \\
\hline The physician teachers were enthusiastic & 0.142 & 0.017 & -0.064 & 0.354 & 0.035 & 0.568 \\
\hline The physician teachers took enough time & 0.123 & 0.031 & 0.040 & 0.502 & 0.046 & 0.432 \\
\hline The programme was a worthwhile learning experience & 0.216 & $<0.001$ & 0.143 & 0.014 & 0.026 & 0.620 \\
\hline \multicolumn{7}{|l|}{ Student attitudes towards community health care } \\
\hline \multicolumn{7}{|l|}{ Post-training } \\
\hline I think practising community health care is worthwhile & 0.206 & $<0.001$ & -0.066 & 0.257 & 0.036 & 0.067 \\
\hline I am confident about practising community health care & 0.078 & 0.049 & -0.006 & 0.892 & 0.004 & 0.531 \\
\hline \multicolumn{7}{|l|}{ Difference (Post-Pre) } \\
\hline I think practising community health care is worthwhile & 0.376 & $<0.001$ & 0.367 & $<0.001$ & 0.040 & 0.354 \\
\hline I am confident about practising community health care & 0.148 & $<0.001$ & 0.052 & 0.262 & -0.032 & 0.448 \\
\hline
\end{tabular}

${ }^{*}$ Difference between before and after the clerkship (Post-Pre); ${ }^{\dagger}$ Pearson's correlation coefficient; ${ }^{\ddagger}$ multivariate regression coefficient with all items related by bivariate analysis

\section{Conflict of Interest}

The authors declare that they have no conflict of interest.

\section{References}

1. Starfield B, Shi L, Macinko J. Contribution of primary care to health systems and health. Milbank Q. 2005;83:457502 .

2. Nusbaum NJ. Commentary: physician retirement and physician shortages. J Community Health. 2009;34:353-6.

3. Kuehn BM. Reports warn of primary care shortage. JAMA. 2008;300:1872, 1874-5.

4. Matsumoto M, Inoue K, Farmer J, Inada H, Kajii E. Geographic distribution of primary care physicians in Japan and Britain. Health Place. 2010;16:164-6.

5. Smith SR. A recipe for medical schools to produce primary care physicians. N Engl J Med. 2011;364:496-7.

6. Lakhan SE, Laird C. Addressing the primary care physician shortage in an evolving medical workforce. Int Arch Med. 2009;2:14.

7. Kozu T. Medical education in Japan. Acad Med. 2006;81:1069-75.

8. Teo A. The current state of medical education in Japan: a system under reform. Med Educ. 2007;41:302-8.

9. Coordinating Council on revising the model core curriculum: Model core curriculum in medical education, the guideline for the educational programme. Revised edition in 2007. [cited 2011 July 30]. Available from: http://www.mext.go.jp/b_menu/shingi/chousa/koutou/033/ toushin/1217987_1703.html.

10. Ganguli I. The case for primary care-a medical student's perspective. N Engl J Med. 2010;363:207-9.

11. Habbick BF, Leeder SR. Orienting medical education to community need: a review. Med Educ. 1996;30:163-71.
12. Murray E, Modell M. Community-based teaching: the challenges. Br J Gen Pract. 1999;49(442):395-8.

13. Takayashiki A, Okayama M, Mise J, Ohtaki J, Nakamura Y, Kajii E. National survey of primary care curricula for undergraduate medical students in Japan. Med Educ (Japan). 2003;34:215-22.

14. Howe A. Teaching in practice: a qualitative factor analysis of community-based teaching. Med Educ. 2000;34(9):762-8.

15. Elnicki DM, Kolarik R, Bardella I. Third-year medical students' perceptions of effective teaching behaviors in a multidisciplinary ambulatory clerkship. Acad Med. 2003;78:815-9.

16. Elzubeir M, Rizk D. Evaluating the quality of teaching in medical education: are we using the evidence for both formative and summative purposes? Med Teach. 2002;24:313-9.

17. Svab I, Petek-Ster M. Long-term evaluation of undergraduate family medicine curriculum in Slovenia. Srp Arh Celok Lek. 2008;136:274-9.

18. Chenot JF, Kochen MM, Himmel W. Student evaluation of a primary care clerkship: quality assurance and identification of potential for improvement. BMC Med Educ. 2009;9:17.

19. Community-based education of health personnel. Report of a WHO study group. World Health Organ Tech Rep Ser. 1987;746:1-89.

20. Okayama M, Kajii E. Does community-based education increase students' motivation to practice community health care? - a cross sectional study. BMC Med Educ. 2011;11:19.

21. Okayama M, Kajii E. Undergraduate medical education in a community: a community-based clinical clerkship. Med Educ (Japan). 2003;34:171-6. 
22. Editorial Committee of Chiiki-iryou hakusyo in Jichi Medical University. Chiiki-iryou hakusyo (the white paper on community health care). 2nd ed. Tochigi, Japan: Jichi Medical University; 2007.

23. Okayama M, Kajii E. Educational effects of a standardized program for community-based clinical clerkships. Med Educ (Japan). 2004;35:197-202.

24. Howe A, Ives G. Does community-based experience alter career preference? New evidence from a prospective longitudinal cohort study of undergraduate medical students. Med Educ. 2001;35:391-7.

25. Grayson MS, Klein M, Franke KB. Impact of a first-year primary care experience on residency choice. J Gen Intern Med. 2001;16:860-3.

26. Sinclair HK, Ritchie LD, Lee AJ. A future career in general practice? A longitudinal study of medical students and pre-registration house officers. Eur J Gen Pract. 2006;12:120-7.

27. Wartman SA. Research in medical education: the challenge for the next decade. Acad Med. 1994;69:608-14.

28. Shipengrover JA, James PA. Measuring instructional quality in community-orientated medical education: looking into the black box. Med Educ. 1999;33:846-53.

29. Thistlethwaite J, Kidd MR, Leeder S, Shaw T, Corcoran $\mathrm{K}$. Enhancing the choice of general practice as a career. Aust Fam Physician. 2008;37:964-8.

30. Bennett KL, Phillips JP. Finding, recruiting, and sustaining the future primary care physician workforce: a new theoretical model of specialty choice process. Acad Med. 2010 Oct;85(10 Suppl):S81-8.

31. Rabinowitz HK, Diamond JJ, Markham FW, Paynter NP. Critical factors for designing programs to increase the supply and retention of rural primary care physicians. JAMA. 2001;286(9):1041-8.

32. Ministry of Education, Culture, Sports, Science and Technology: Report on Social Basic Survey 2010. [cited 2011 July 30]. Available from: http://www.mext.go.jp/b_menu/houdou/22/08/1296402.htm.

33. Barrett FA, Lipsky MS, Lutfiyya MN. The impact of rural training experiences on medical students: a critical review. Acad Med. 2011;86:259-63.

34. Tsuda T, Aoyama H, Froom J. Primary health care in Japan and the United States. Soc Sci Med. 1994;38:489-95. 